\title{
BMJ Open Characteristics of pneumonia deaths after an earthquake and tsunami: an ecological study of 5.7 million participants in 131 municipalities, Japan
}

\author{
Yosuke Shibata, ${ }^{1}$ Toshiyuki Ojima, ${ }^{1}$ Yasutake Tomata, ${ }^{2}$ Eisaku Okada, ${ }^{1}$ \\ Mieko Nakamura, ${ }^{1}$ Miyuki Kawado, ${ }^{3}$ Shuji Hashimoto ${ }^{3}$
}

To cite: Shibata Y, Ojima T, Tomata $Y$, et al.

Characteristics of pneumonia deaths after an earthquake and tsunami: an ecological study of 5.7 million participants in 131 municipalities, Japan. BMJ Open 2016;6: 009190. doi:10.1136/bmjopen-2015009190

- Prepublication history for this paper is available online. To view these files please visit the journal online (http://dx.doi.org/10.1136/ bmjopen-2015-009190).

Received 25 June 2015 Accepted 7 December 2015

\section{(a) CrossMark}

${ }^{1}$ Department of Community Health and Preventive Medicine, Hamamatsu University School of Medicine, Hamamatsu, Shizuoka, Japan ${ }^{2}$ Department of Public Health and Forensic Medicine, Tohoku University Graduate School of Medicine, Sendai, Miyagi, Japan

${ }^{3}$ Department of Hygiene, Fujita Health University School of Medicine, Toyoake, Aichi, Japan

Correspondence to Dr Yosuke Shibata; shibata-yosuke@umin.ac.jp

\section{ABSTRACT}

Objective: On 11 March 2011, the Great East Japan Earthquake struck off Japan. Although some studies showed that the earthquake increased the risk of pneumonia death, no study reported whether and how much a tsunami increased the risk. We examined the risk for pneumonia death after the earthquake/tsunami.

Design: This is an ecological study.

Setting: Data on population and pneumonia deaths obtained from the Vital Statistics 2010 and 2012, National Census 2010 and Basic Resident Register 2010 and 2012 in Japan.

Participants: About 5.7 million participants residing in Miyagi, Iwate and Fukushima Prefectures during 1 year after the disaster were targeted. All municipalities $(n=131)$ were categorised into inland $(n=93)$, that is, the earthquake-impacted area, and coastal types $(n=38)$, that is, the earthquake-impacted and tsunami-impacted area.

Outcome measures: The number of pneumonia deaths per week was totalled from 12 March 2010 to 9 March 2012. The number of observed pneumonia deaths $(0)$ and the sum of the sex and age classes in the observed population multiplied by the sex and age classes of expected pneumonia mortality $(E)$ were calculated. Expected pneumonia mortality was the pneumonia mortality during the year before.

Standardised mortality ratios (SMRs) were calculated for pneumonia deaths (0/E), adjusting for sex and age using the indirect method. SMRs were then calculated by coastal and inland municipalities.

Results: 6603 participants died of pneumonia during 1 year after the earthquake. SMRs increased significantly during the 1st-12th weeks. In the 2nd week, SMRs in coastal and inland municipalities were $2.49(95 \% \mathrm{Cl} 2.02$ to 7.64$)$ and $1.48(95 \%$ Cl 1.24 to 2.61), respectively. SMRs of coastal municipalities were higher than those of inland municipalities.

Conclusions: An earthquake increased the risk of pneumonia death and tsunamis additionally increased the risk.

\section{Strengths and limitations of this study}

- This paper presents data from a large population-based ecological study.

- High-validity data, with national statistics covering all death information, were used.

- Earthquake and tsunami for pneumonia risk were analysed in a single article.

Population movement was not considered.

\section{BACKGROUND}

The Great East Japan Earthquake with a magnitude of 9.0 struck off Japan on 11 March 2011, causing unprecedented damage: 19074 deaths, 2633 missing persons, 6219 injured, 127361 buildings completely destroyed and 273268 partially destroyed. ${ }^{1}$ The epicentre was approximately $70 \mathrm{~km}$ east of the Oshika Peninsula of Miyagi Prefecture and the hypocentre at an underwater depth was $24 \mathrm{~km} .{ }^{1}$ It was the most powerful earthquake ever recorded to have struck off Japan. The earthquake then caused a large tsunami which reached shore almost immediately, $30 \mathrm{~min}$ after the earthquake. ${ }^{1}$ The Japan Meteorological Agency reported tsunami heights of more than $10 \mathrm{~m}^{2}{ }^{2}$ Miyagi, Iwate and Fukushima Prefectures suffered heavy damage, and $99.4 \%$ of the deaths occurred in these three prefectures. ${ }^{1}$

Some studies of the Great East Japan Earthquake of 2011 reported that pneumonia occurred after the earthquake. ${ }^{3-7}$ During $3 \frac{1}{2}$ months following the earthquake, the incidence of pneumonia hospitalisations increased by 5.7 times. $^{3}$ The number of patients in one hospital after the earthquake was 3.68/100 000 compared with $0.47 / 100000$ in a regular year. ${ }^{4}$ However, two major infectious diseases occurred after a tsunami: wound infection and aspiration pneumonia. ${ }^{8}$ Several 
clinical reports showed that tsunami survivors suffered from pneumonia. ${ }^{9-12}$ Tsunami survivors aspirate water, as well as solid matter and dust. A tsunami reportedly hit an area where Burkholderia pseudomallei is endemic, ${ }^{9}$ and Escherichia coli and Legionella pneumonia have been rarely seen in a community-acquired pneumonia. ${ }^{10} 11{ }^{13}$ Severe pneumonia associated with aspiration of tsunami was known as 'tsunami lung'. 1214

The risk of pneumonia death was increased by the earthquake and tsunami, respectively. However, it is unclear whether and how much a tsunami increased the risk of pneumonia death. It is important for emergency medicine to make the matter clear, because an earthquake with tsunami causes catastrophic damage and the medical staff must use limited medical resources effectively. Hence, the aim of the present study was to determine the risk for pneumonia death after the earthquake/tsunami.

\section{METHODS}

\section{Study population}

This is an ecological study in Japan. Data from the 131 municipalities (population about 5.7 million) in Japan 2010-2012 were used. All participants residing in Miyagi, Iwate and Fukushima Prefectures were examined, including their 131 municipalities, both coastal $(n=38)$ and inland $(\mathrm{n}=93)$ (figure 1).

\section{Data sources}

The Vital Statistics 2010-2012, National Census 2010 and Basic Resident Register 2010-2012 in Japan were used. Death data from Vital Statistics were obtained from public health centres in prefectures, which then sent the data to the Ministry of Health, Labour and Welfare. Data collection by public health centres was temporarily suspended owing to earthquakes, but public health centres acquired all data and sent them to the respective prefecture by June 2011. We defined pneumonia death using the International Classification of Diseases (ICD) 10. 'Pneumonia' was defined as J12 to J18. Our study classification did not include 'Exposure to forces of nature (X30 to X39),' including 'Victim of earthquake (X34)'. Data on pneumonia deaths were obtained during 1 year before and after the earthquake.

The population data were obtained from the Basic Resident Register and National Census. The Basic Resident Register was maintained by municipalities and reported every month. The weekly population was calculated using the linear estimation method. Populations from the Basic Resident Resister were categorised in 17 age classes (0-4 to $80+$ age class). The National Census is taken every 5 years; the latest is the 2010 version. Populations from the National Census were categorised into 18 age classes ( $0-4$ to $85+$ age class). We allocated the $80+$ age class to the $80-84$ and $85+$ age class. The same proportional distribution was maintained in the National Census.

\section{Statistics}

Standardised mortality ratios (SMRs) were calculated to show how many times larger the pneumonia mortality is

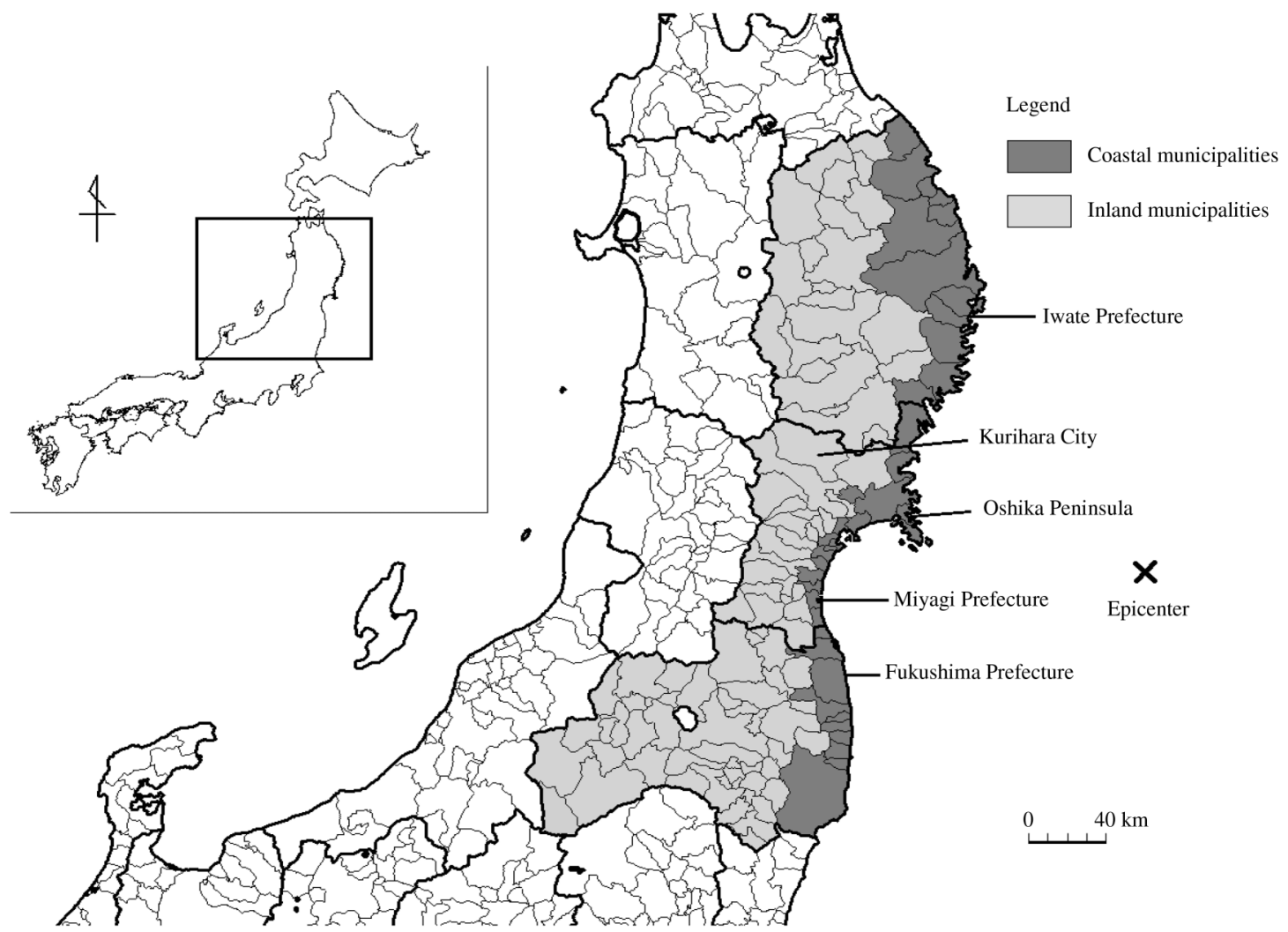

Figure 1 Location of Iwate, Miyagi and Fukushima Prefectures and epicentre of the Great East Japan Earthquake. 
compared to that of 1 year before adjusting for sex and age. ${ }^{15}$ In detail, the sex-specific and age-specific pneumonia mortality before the earthquake (pre-52nd to pre-1st weeks, standard period) was multiplied by the sex-specific and age-specific population after the earthquake (post-1st to post-52nd weeks, comparison period) to obtain the products by week. The total of the products were calculated to obtain the expected number of pneumonia deaths (E). The total number of observed pneumonia deaths (O) was calculated. SMRs were obtained by $\mathrm{O}$ divided by $\mathrm{E}$. The $95 \%$ CIs of SMRs were estimated using the Poisson distribution. SMRs were calculated for all municipalities and were additionally calculated for coastal and inland municipalities as one group. All analyses were performed with the SAS V.9.3 (SAS, Institute, Cary, North Carolina, USA).

\section{RESULTS}

\section{Characteristics of population}

In the three prefectures aforementioned, 6603 participants died of pneumonia during the year after the earthquake, and 5776 participants during the year before (table 1). A total of 4488 participants died of pneumonia during 1 year after in inland municipalities and 4016 participants died during 1 year before. In coastal municipalities, a total of 2115 participants died of pneumonia during 1 year after and 1760 participants died during 1 year before (table 1 ).

\section{Trend of pneumonia deaths and SMRs for pneumonia deaths}

The number of pneumonia deaths increased after the earthquake (figure 2). In inland municipalities, pneumonia deaths were $<100$ before the earthquake and increased to 120 after it. In coastal municipalities, although pneumonia deaths were fewer than 50 before the earthquake, the number increased to 90 after it. The number of pneumonia deaths in the three prefectures increased after the earthquake. The ratio of the number of pneumonia deaths 1 year after to that of 1 year before was 1.14 .
The SMRs for pneumonia death increased during the 1st-12th weeks after the earthquake (table 2). The numbers of expected deaths, observed deaths and excess deaths during the 1st-12th weeks were 602,1072 and 470, respectively. The highest SMR was $1.78(95 \%$ CI 1.56 to 3.64) in the 2nd week. During the 2nd-5th weeks, SMRs showed a relatively high level, but they steadily decreased by the 12th week.

SMRs in coastal municipalities were higher than in inland municipalities. The SMRs in the 2nd week in coastal and inland municipalities were 2.49 (95\% CI 2.02 to 7.64 ) and 1.48 (95\% CI 1.24 to 2.61 ), respectively (figure 2 and table 2).

\section{DISCUSSION}

In this study, the risk during the 2nd-4th weeks was about twofold in the coastal municipalities. A significantly increased risk of pneumonia death occurred during the 1st-12th weeks after the Great East Japan Earthquake. To the best of our knowledge, this is the first study to report that the risk of pneumonia death was additionally increased in coastal municipalities.

Our study showed that association between disaster and pneumonia death. In the South Asian Earthquake of 2005, mobile clinics documented that infectious diseases accounted for at least $65 \%$ of all illness. ${ }^{16}$ The following surveillance also showed that acute respiratory infection, including pneumonia, continued to be the most common cause of clinic visits. In the Hanshin-Awaji Earthquake, the proportion of patients with respiratory infection was more than half of all infectious diseases. ${ }^{17}$ Previous studies suggested that several factors have contributed to pneumonia death, although the causal mechanism was not fully established. ${ }^{3}{ }^{4} \quad 18 \quad 19$ Lack of appropriate nutrition, loss of regular medicines, psychological stress and cold temperature might increase the risk of pneumonia death. ${ }^{3} 41819$ Additionally, the accident at the atomic power plant in Fukushima Prefecture forced residents to evacuate their living area. It led to a high population density in the shelter and might have increased the risk of pneumonia death. Generally, the

\begin{tabular}{|c|c|c|c|}
\hline Characteristics & All municipalities & Coastal municipalities & Inland municipalities \\
\hline Population & 5725977 & 1801324 & 3924653 \\
\hline \multicolumn{4}{|l|}{ Sex } \\
\hline Female (\%) & 2948873 (51.5) & $925551(51.4)$ & 2023322 (51.6) \\
\hline Male (\%) & 2777104 (48.5) & 875773 (48.6) & 1901331 (48.4) \\
\hline \multicolumn{4}{|l|}{ Age, years } \\
\hline$-14(\%)$ & 766815 (13.4) & $241192(13.4)$ & $525623(13.4)$ \\
\hline $15-64(\%)$ & 3579121 (62.5) & $1123719(62.4)$ & 2455402 (62.6) \\
\hline $65+(\%)$ & 1380041 (24.1) & $436413(24.2)$ & $943628(24.0)$ \\
\hline \multirow{2}{*}{\multicolumn{4}{|c|}{$\begin{array}{l}\text { Pneumonia deaths } \\
\mathrm{N}\end{array}$}} \\
\hline & & & \\
\hline One year before & 5776 & 1760 & 4016 \\
\hline One year after & 6603 & 2115 & 4488 \\
\hline
\end{tabular}


Figure 2 Number of pneumonia deaths during 1 year before and after the earthquake.

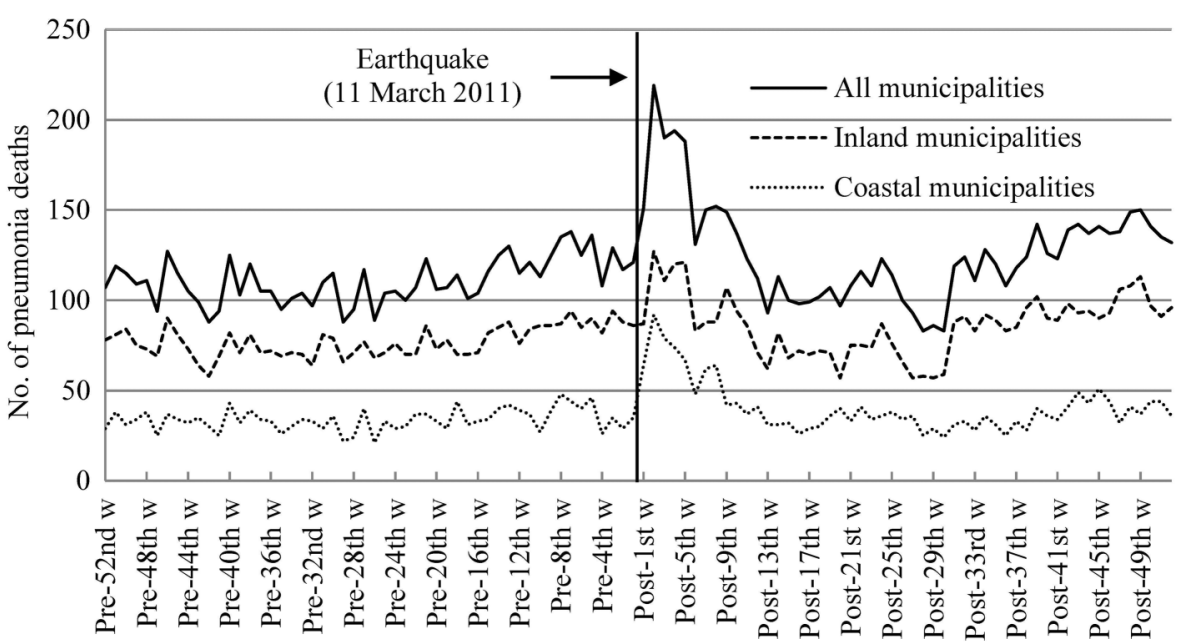

risk of pneumonia death in elderly people was higher than that in young people. The ageing rate of $24.1 \%$ might have also contributed to this outbreak.

Our study showed that SMRs of coastal municipalities were higher than for inland municipalities, although the highest seismic intensity area for the earthquake was Kurihara City, an inland municipality. These findings revealed that a tsunami might increase the pneumonia death risk in addition to the effects of the earthquake. We propose two hypotheses: first, tsunami lung, which involves aspiration of the tsunami, increased the pneumonia death risk, ${ }^{121420}$ and second, a tsunami-impacted area was more damaging than an earthquake-impacted one. A tsunami raised more dust. Previous studies indicated that the number of hospitalised patients with pneumonia was related to destruction ratios, ${ }^{21}$ and showed that the higher percentage of households flooded was associated with a higher risk of indirect mortality. ${ }^{22}$ Many tsunami survivors lost their homes and had to flee to shelters in the destroyed environment. The medical staff were not stationed in all shelters. The tsunami also destroyed transport infrastructure such as roads and railway systems. Tsunami survivors could thus not go to the hospital and obtain sufficient medical care. However, only one study reported that a tsunami did not increase the risk of infections in Sri Lanka in $2004,{ }^{23}$ for example. The different results were caused by several factors. The proportion of people 65 years or older in Sri Lanka is less than that of Japan. ${ }^{24}$ Sri Lanka has a tropical climate with warm temperature, and death information was obtained from householders.

Our study has several strengths. First, we analysed both the earthquake and tsunami for risk of pneumonia

Table 2 Standardised mortality ratios (SMRs) for pneumonia compared with 1 year before

\begin{tabular}{|c|c|c|c|c|c|c|}
\hline \multirow[b]{2}{*}{ Earthquake (11 March 2011) } & \multicolumn{2}{|c|}{ All municipalities } & \multicolumn{2}{|c|}{ Coastal municipalities } & \multicolumn{2}{|c|}{ Inland municipalities } \\
\hline & SMRs & $(95 \% \mathrm{Cl})$ & SMRs & $(95 \% \mathrm{Cl})$ & SMRs & $(95 \% \mathrm{Cl})$ \\
\hline 1st week & 1.37 & (1.16 to 2.20$)$ & 1.93 & (1.50 to 4.77$)$ & 1.13 & (0.91 to 1.58$)$ \\
\hline 2nd week & 1.78 & (1.56 to 3.64$)$ & 2.49 & (2.02 to 7.64$)$ & 1.48 & (1.24 to 2.61$)$ \\
\hline 3rd week & 1.60 & (1.38 to 2.96$)$ & 2.20 & (1.76 to 6.09 ) & 1.34 & (1.11 to 2.17$)$ \\
\hline 4th week & 1.72 & (1.49 to 3.43 ) & 2.19 & (1.73 to 6.05$)$ & 1.52 & (1.27 to 2.79$)$ \\
\hline 5th week & 1.65 & (1.42 to 3.13$)$ & 1.95 & (1.52 to 4.87$)$ & 1.51 & (1.26 to 2.75$)$ \\
\hline 6th week & 1.35 & (1.13 to 2.18$)$ & 1.65 & (1.23 to 3.64$)$ & 1.22 & (0.98 to 1.87$)$ \\
\hline 7th week & 1.15 & (0.97 to 1.55$)$ & 1.58 & (1.22 to 3.22$)$ & 0.96 & (0.77 to 1.14$)$ \\
\hline 8th week & 1.28 & (1.09 to 1.94 ) & 1.80 & (1.40 to 4.18$)$ & 1.06 & (0.86 to 1.39 ) \\
\hline 9th week & 1.38 & (1.17 to 2.25 ) & 1.30 & (0.95 to 2.29 ) & 1.42 & (1.17 to 2.45$)$ \\
\hline 10th week & 1.35 & (1.14 to 2.17 ) & 1.40 & (1.03 to 2.67 ) & 1.33 & (1.08 to 2.18 ) \\
\hline 11 th week & 1.36 & (1.13 to 2.20$)$ & 1.36 & (0.97 to 2.58 ) & 1.35 & (1.09 to 2.27 ) \\
\hline 12th week & 1.16 & (0.96 to 1.62$)$ & 1.41 & (1.03 to 2.73 ) & 1.05 & (0.83 to 1.40$)$ \\
\hline 13th week & 0.73 & (0.59 to 0.65$)$ & 0.81 & (0.56 to 0.93 ) & 0.69 & (0.53 to 0.62 ) \\
\hline 14th week & 1.07 & (0.88 to 1.37 ) & 0.98 & (0.67 to 1.37 ) & 1.10 & (0.88 to 1.52 ) \\
\hline 15th week & 0.81 & (0.66 to 0.80 ) & 0.86 & (0.60 to 1.07 ) & 0.79 & (0.62 to 0.79 ) \\
\hline 16th week & 0.91 & (0.74 to 1.00 ) & 0.80 & (0.54 to 0.96 ) & 0.95 & (0.75 to 1.14$)$ \\
\hline 17th week & 0.92 & (0.75 to 1.04$)$ & 0.90 & (0.61 to 1.17 ) & 0.93 & (0.73 to 1.10$)$ \\
\hline 18th week & 1.05 & (0.86 to 1.34 ) & 1.02 & (0.70 to 1.51 ) & 1.06 & (0.83 to 1.42$)$ \\
\hline 19th week & 1.04 & (0.85 to 1.30$)$ & 1.16 & (0.82 to 1.88 ) & 0.98 & (0.77 to 1.23$)$ \\
\hline 20th week & 0.91 & (0.74 to 1.01 ) & 1.25 & (0.90 to 2.15 ) & 0.76 & (0.58 to 0.76$)$ \\
\hline
\end{tabular}


death in a single article. No study to date has examined the relationship between some natural disasters and pneumonia death risk in a single article. Our results showed that tsunami survivors need intensive care and prevention for pneumonia death. Second, we used large population-based data. Previous studies were reported from some hospitals or clinics, but did not include participants who died of pneumonia at home and shelters. Finally, we used high validity data, with national statistics covering all death information.

However, our study has some limitations. First, it classified coastal municipalities as tsunami-impacted areas. It was difficult to classify areas into tsunami-impacted areas accurately. Therefore, coastal municipalities include some areas with no tsunami damage. This leads to underestimation of the tsunami effects on the risk of pneumonia death. Second, population movement was not considered. Some people must have evacuated from coastal municipalities to inland municipalities or inland areas of the same municipalities. Therefore, the number of pneumonia deaths must have been higher in inland areas than in coastal areas. This also leads to an underestimation of tsunami effects on the risk of pneumonia death.

\section{CONCLUSION}

Our study showed that a tsunami additionally increased the risk of pneumonia death. Our observations underscore the need for emergency preparedness for pneumonia. ${ }^{25}$

Contributors YS, TO, MK and SH contributed to the study conception/design. MK and SH contributed to the data collection. YS, TO and SH conducted the data analysis. YS drafted the article. TO, YT, EO, MN, MK and SH revised the article and reviewed the draft of the article.

Funding This work was supported by Health Sciences Research Grants (H24-Toukei-Ippan-006, H25-Kenki-Shitei-002 [fukkou]) from the Ministry of Health, Labour and Welfare of Japan.

Competing interests None declared.

Provenance and peer review Not commissioned; externally peer reviewed.

Data sharing statement Additional data can be accessed via the Dryad data repository at http://datadryad.org/ with the doi:10.5061/dryad.1k01d.

Open Access This is an Open Access article distributed in accordance with the Creative Commons Attribution Non Commercial (CC BY-NC 4.0) license, which permits others to distribute, remix, adapt, build upon this work noncommercially, and license their derivative works on different terms, provided the original work is properly cited and the use is non-commercial. See: http:// creativecommons.org/licenses/by-nc/4.0/

\section{REFERENCES}

1. Fire and Disaster Management Agency of the Ministry of Internal Affairs and Communications. Heisei23nen Tohokuchihotaiheyookijishin nituite (150hou) (About Tohoku region earthquake (Version 150)), 2014 (in Japanese). http://www.fdma.go.jp/bn/higaihou/pdf/jishin/150.pdf

2. Japan Meteorological Agency. Monthly report on earthquakes and volcanoes in Japan. 2011. http://www.data.jma.go.jp/svd/eqev/data/ gaikyo/monthly/201103/monthly201103.pdf
3. Daito H, Suzuki M, Shiihara J, et al. Impact of the Tohoku earthquake and tsunami on pneumonia hospitalisations and mortality among adults in northern Miyagi, Japan: a multicentre observational study. Thorax 2013;68:544-50.

4. Aoyagi T, Yamada M, Kunishima $\mathrm{H}$, et al. Characteristics of infectious diseases in hospitalized patients during the early phase after the 2011 Great East Japan earthquake: pneumonia as a significant reason for hospital care. Chest 2013;143:349-56.

5. Yamanda S, Hanagama M, Kobayashi S, et al. The impact of the 2011 Great East Japan Earthquake on hospitalisation for respiratory disease in a rapidly aging society: a retrospective descriptive and cross-sectional study at the disaster base hospital in Ishinomaki. BMJ Open 2013;3:e000865.

6. Suzuki M, Uwano C, Ohrui T, et al. Shelter-acquired pneumonia after a catastrophic earthquake in Japan. J Am Geriatr Soc 2011;59:1968-70

7. Takahashi $\mathrm{T}$, Goto $\mathrm{M}$, Yoshida $\mathrm{H}$, et al. Infectious diseases after the 2011 Great East Japan Earthquake. J Exp Clin Med 2012;4:20-3.

8. Kao AY, Munandar R, Ferrara SL, et al. Case records of the Massachusetts General Hospital. Case 19-2005. A 17-year-old girl with respiratory distress and hemiparesis after surviving a tsunami. N Engl J Med 2005;352:2628-36.

9. Kongsaengdao S, Bunnag S, Siriwiwattnakul N. Treatment of survivors after the tsunami. N Engl J Med 2005;352:2654-5.

10. Ohkouchi S, Ebina M, Kamei K, et al. Fatal acute interstitial pneumonia in a worker making chips from wooden debris generated by the Great East Japan Earthquake and tsunami. Respir Investig 2012;50:129-34.

11. Igusa R, Narumi S, Murakami K, et al. Escherichia coli pneumonia in combination with fungal sinusitis and meningitis in a tsunami survivor after the Great East Japan Earthquake. Tohoku J Exp Med 2012;227:179-84.

12. Allworth AM. Tsunami lung: a necrotising pneumonia in survivors of the Asian tsunami. Med J Aust 2005;182:364.

13. Nakadate $\mathrm{T}$, Nakamura $\mathrm{Y}, \mathrm{Yamauchii} \mathrm{K}$, et al. Two cases of severe pneumonia after the 2011 Great East Japan Earthquake. Western Pac Surveill Response J 2012;3:67-70.

14. Inoue $\mathrm{Y}$, Fujino $\mathrm{Y}$, Onodera $\mathrm{M}$, et al. Tsunami lung. $J$ Anesth 2012;26:246-9.

15. William AO. Essential epidemiology. Long Grove, IL: Waveland Press, Inc. 2002:101-3.

16. Takakura R, Himeno S, Kanayama Y, et al. Follow-up after the Hanshin-Awaji earthquake: diverse influences on pneumonia, bronchial asthma, peptic ulcer and diabetes mellitus. Intern Med 1997:36:87-91.

17. Brennan RJ, Waldman RJ. The south Asian earthquake six months later-an ongoing crisis. N Engl J Med 2006;354:1769-71.

18. Tomata $\mathrm{Y}$, Kakizaki M, Suzuki Y, et al. Impact of the 2011 Great East Japan Earthquake and tsunami on functional disability among older people: a longitudinal comparison of disability prevalence among Japanese municipalities. J Epidemiol Community Health 2014;68:530-3.

19. Tanida N. What happened to elderly people in the great Hanshin earthquake. BMJ 1996;313:1133-5.

20. Hiruma T, Nakamura K, Inokuchi R, et al. Tsunami lung accompanied by multiple disorders. Am J Respir Crit Care Med 2013;187:110-11

21. Matsuoka T, Yoshioka T, Oda J, et al. The impact of a catastrophic earthquake on morbidity rates for various illnesses. Public Health 2000;114:249-53.

22. Uchimura M, Kizuki M, Takano T, et al. Impact of the 2011 Great East Japan Earthquake on community health: ecological time series on transient increase in indirect mortality and recovery of health and long-term-care system. J Epidemiol Community Health 2014;68:874-82.

23. Nishikiori N, Abe T, Costa DG, et al. Timing of mortality among internally displaced persons due to the tsunami in Sri Lanka: cross sectional household survey. BMJ 2006;332:334-5.

24. Department of Census and Statistics. Census of Population and Housing. 2012. http://www.statistics.gov.Ik/PopHouSat/VitalStatistics/ EVE2011_FinalReport.pdf

25. The Japan Geriatrics Society. Koureisha saigaiji iryou guideline (Medical care guideline at disaster for elderly). 2011 (in Japanese). http://www.jpn-geriat-soc.or.jp/member/kaikai/koku_saigai-guideline. $\mathrm{html}$ 